\title{
Effects of Yoga, Exercise and Prayer on the Quality of Life
}

\author{
Zeenat Fatima ${ }^{1}$, Dr Shahina Maqbool ${ }^{2}$
}

\section{ABSTRACT}

Background of the study: This paper aims to find out the effects of Yoga, Exercise and Prayers on the quality of life of people. It is found that people who regularly practice yoga or do exercise and indulge in continuous prayers which is a kind of meditation are healthier and living a peaceful life. It gives them an inner strength which is helpful in leading a quality of life. Practising yoga or exercise and the daily prayers unites the mind and the heart of the individual and people are able to perceive the inner and outer world more positively. Material and Method: 30 subjects aged 18-60 years who regularly practice yoga or any exercise and indulge in regular prayer will be randomly taken and the questionnaire of WHO quality of life (WHOQOL-BREF) will be administered. Result and Discussion: The result of this study shows that there is a positive effect of yoga, exercise and prayer on the quality of life. Individuals who practise yoga, exercise and indulge in daily prayers are more satisfied healthy and there is a connection between their mind and body.

Keywords: Yoga, prayer, exercise, Quality of Life.

Yoga is a Hindu spiritual and ascetic discipline a part of which, including breath control, simple meditation and the adoption of specific bodily postures, widely practised for health and relaxation.

The word Yoga comes from the Sanskrit root yuj, which means "to join” or "to yoke”. Yoga is a practical aid, not a religion. It is an ancient art based on a harmonizing system of development for the body, mind and spirit. The continued practice of yoga will lead us to a sense of peace and well-being and also a feeling of being at one with our environment. Its practice makes the body strong and flexible, also improves the functioning of the respiratory, circulating, digestive and hormonal systems. In yoga through a step by step process we try to dissolve the ego consciousness in the soul consciousness. The Yoga Upnishads identify four types of yogaMantra yoga, Laya yoga, Raja yoga and Hatha yoga. In a German study published in 2005, 24 women who described themselves as "emotionally distressed" took two 90 minute yoga classes

\footnotetext{
${ }^{1}$ Ph.D Scholar, Aligarh Muslim University, Aligarh

${ }^{2}$ Prof. Dept of Psychology, Aligarh Muslim University, Aligarh

*Responding Author

(C) 2016 I Z Fatima, S Maqbool; licensee IJIP. This is an Open Access Research distributed under the terms of the Creative Commons Attribution License (http://creativecommons.org/licenses/by/2.0), which permits unrestricted use, distribution, and reproduction in any Medium, provided the original work is properly cited.
} 


\section{Effects of Yoga, Exercise and Prayer on the Quality of Life}

for a week for three months. Women in a control group maintained their normal activities and were asked not to begin an exercise or stress reduction program during the study period. At the end of the three months, women in the yoga group reported improvements in perceived stress, depression, anxiety, energy, fatigue and well-being. One uncontrolled, descriptive 2005 study examined the effects of a single yoga class for inpatients at a New Hampshire psychiatric hospital. The 113 participants included patients with bipolar disorder, major depression, and schizophrenia. After the class, average levels of tension, anxiety, depression, anger, hostility, and fatigue dropped significantly, as measured by the Profile of Mood States, a standard 65-item questionnaire that participants answered on their own before and after the class. Patients who chose to participate in additional classes experienced similar short-term positive effects.

Further controlled trials of yoga practice have demonstrated improvements in mood and quality of life for the elderly, people caring for patients with dementia, breast cancer survivors, and patients with epilepsy. In a 2011 study, funded by (NCCIH) National Centre for Complementary and Integrative Health, researchers compared yoga with conventional stretching exercises or a self care book in 228 adults with chronic low back pain. According to the 2007 National health Interview Survey (NHIS), which included a comprehensive survey on the use of complementary health approaches by Americans, yoga is the sixth most commonly used complementary health practise among adults. More than 13 million adults practised yoga in the previous year and between 2002 and 2007 NHIS use of yoga increased by 1\% or 3 million people approximately.

\section{Exercise:}

Exercise is physical activity that is planned, structured and repetitive for the purpose of conditioning the body. Exercise consists of cardiovascular conditioning strength and resistance training and flexibility. Exercise is essential for improving overall health, maintaining fitness and helping to prevent the development of obesity, hypertension and cardiovascular disease. Surveys conducted by the Centres for Disease Control and Prevention (CDC) indicate that 61.5\% of children aged 9 to 13 years do not participate in any organised physical activity (for example sports, dance classes) and 22.65 are not physically active during their free time. According to the American Obesity Association, approximately 30\% of children and adolescents aged 6 to 19 years are overweight and 15\% are obese. Exercise can be divided into three broad categoriesAerobic, Anaerobic and Agility training. Aerobic exercise has the aim of improving the body's consumption of oxygen. Most aerobic exercises are done at moderate levels of intensity for a longer periods compared to other categories of exercise. The aim of anaerobic exercise is to build power, strength and muscle. The muscles are exercised at high intensity for short durations that is no more than two minutes. Agility training aims to improve a person's ability to speed up and slowdown, change directions while maintaining balance and control. During 2010 a study was conducted by Randi Jepsen, Eivind Aadland, John R. Anderson and Gerd K Nating, in which a total of 49 severely obese individuals who began a lifestyle intervention programme in Western Norway agreed to participate. Research suggests that physical activity plays a role in weight reduction and improved health. There is a positive relationship between physical activity and life 


\section{Effects of Yoga, Exercise and Prayer on the Quality of Life}

satisfaction. A Surgeons General's report (Anonymous 1996) addresses the finding that continuous and consistent physical activity is proven to enhance longevity and the quality of life for people of all ages. The report notes that although it has been recognized for years that regular physical activity can lead to substantial health benefits, also promotes psychological well-being and reduce feelings of anxiety and depression.

\section{Prayer:}

The word prayer is derived from the two Sanskrit words 'pra' and 'artha' meaning pleading fervently. In other words, it is asking God for something with intense yearning. Prayer includes respect, love, pleading and faith. By praying, we express our helplessness and endow the doership of a task of God. Praying benefits us at a level of action, thought and attitude. It is an effective means of awakening our spiritual emotion (bhav) and experiencing communication with God and the Bliss (Anand) that results from it. There are five major types of prayers:

1. Adoration- In this we praise the greatness of God and we acknowledge our dependence on him in all things.

2. Expiation- In this prayer we acknowledge our sinfulness and ask God for His forgiveness and mercy.

3. Love- Prayers of love and charity are just that expressions of our love for God, the source and object of all love.

4. Petition- In this we ask God for things we need- primarily spiritual needs but physical needs as well.

5. Thanksgiving- Perhaps the most neglected type of prayer is the prayer of thanksgiving.

A study was conducted by Masoud Bahrami, Elaheh Balouchestani, Alireza Amini and Maryam Eghbali for assessing the effect of two praying methods on the life quality of patients suffering from cancer. The present study was conducted in two-staged clinical trial using pre-post test administration in which the researcher examined the effect of two individual and choral praying methods on the life quality of 70 cancer stricken patients. Data collection was performed by World Health Organization Brief Life Quality Questionnaire. The findings indicated the positive effect of praying and supplication on the life quality of cancer stricken patients.

\section{Quality Of Life:}

Quality of life is a general well-being of individuals and societies. Quality of life has a wide range of contexts, including the fields of international development, health care, politics and employment. Quality of life should not be confused with the concept of standard of living, which is based primarily on income. Standard indicators of the quality of life includes not only wealth and employment but also the built environment, physical and mental, health, education, recreation and leisure time and social belonging. According to ecological economist Robert Costanza: While Quality of life has long been an explicit or implicit policy goal , adequate definition and measurement have been elusive. Diverse "objective” and "subjective” indicators across a range of disciplines and scales and recent work on subjective well-being (SWB) surveys 


\section{Effects of Yoga, Exercise and Prayer on the Quality of Life}

and the psychology of happiness have spurred renewed interest. Quality of life may be defined as subjective well-being. Recognising the subjectivity of quality of life is a key to understanding this construct. Quality of life reflects the difference, the gap, between the hopes and expectations of a person and their present experience. Human adaptation is such that life expectations are usually adjusted so as to lie within the realm of what the individual perceives to be possible. This enables people who have difficult life circumstances to maintain a reasonable Quality of life. (Janssen Quality-of-Life Studies).

The approach to the measurement of the quality of life derives from the position that there are a number of domains of living. Each domain contributes to one's overall assessment of the quality of life. The domains include family and friends, work, neighbourhood (shelter), community, health, education, and spirit.

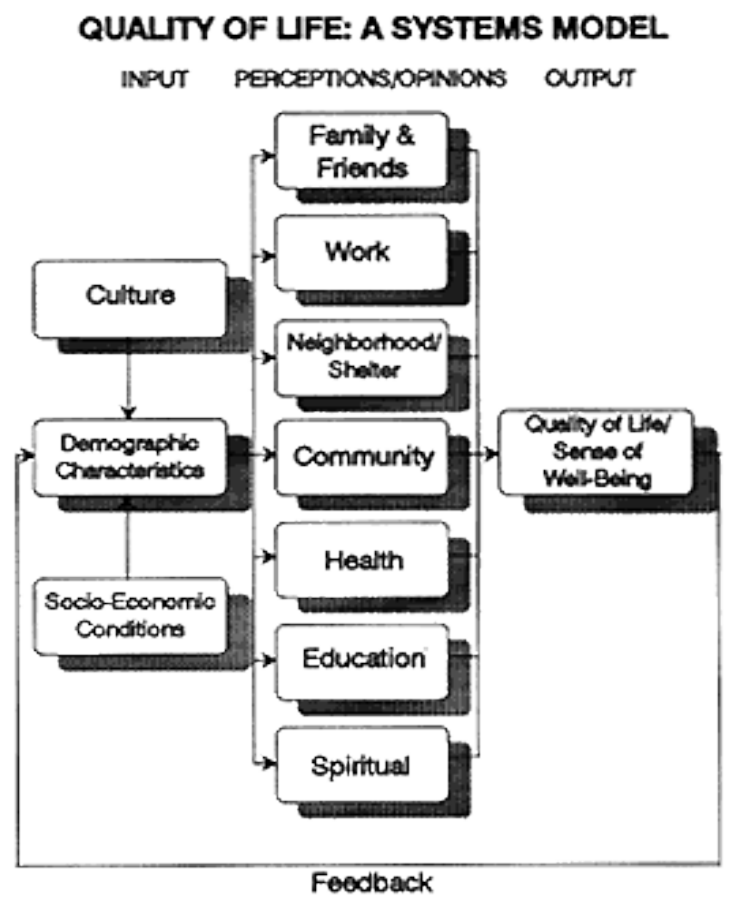

The University of Oklahoma School of Social Work

\section{OBJECTIVE}

- $\quad$ To find out the effects of yoga, exercise and prayer on quality of life.

\section{METHODOLOGY}

\section{Participants:}

The present study was conducted on 60 subjects of the age group between 18 years to 50 years among them 30 were those who regularly practise yoga, exercise and perform regular prayers and the rest 30 were non yogic. The sample was selected randomly.

\section{Procedure:}

The research data was collected by different subjects individually by administering WHOQOLBREF developed by WHOQOL group and contains a total of 26 questions. 24 items are based on 
a 4 domain structure that is, Physical health, Psychological, Social Relationships and Environment, in addition 2 items are from the Overall Quality of Life and General Health facet. The items are based on 5 point Likert Scale ranging from very poor, poor, neither poor nor good, good and very good. Prior to data collection, the researcher has to establish rapport with the subjects and also keeps in mind the subject's readiness to support the purpose. The subjects also told that their responses would be kept confidential and should be utilised for research purpose only. After the completion of this task the data was analysed and interpreted by using appropriate statistical techniques.

\section{RESULT AND DISCUSSION}

The data of the present study was obtained from 30 yogic and 30 non yogic subjects in order to find out the difference in the quality of life of the two groups. The result of this analysis is shown in different tables which are as follows:

TABLE-1, Showing The Comparison Of Total Physical Health Of Yoga And Non-Yoga Practitioners:

\begin{tabular}{|l|l|l|l|l|}
\hline Groups & N & M & S.D & T \\
\hline $\begin{array}{l}\text { Yoga } \\
\text { practitioners }\end{array}$ & 30 & 26.13 & 2.801 & 3.429 \\
\hline $\begin{array}{l}\text { Non Yoga } \\
\text { practitioners }\end{array}$ & 30 & 23.67 & 2.771 & 3.429 \\
\hline
\end{tabular}

Table 1 shows the comparison between the physical health of yoga practitioners and non-yoga practitioners. The mean score of yoga practitioners is 26.13 and for non-yoga practitioners it is 23.67. The standard deviations are 2.801 and 2.771 respectively. The t-value is 3.429 which is significant at .01 level of significance indicating a significant difference between the physical health of yoga practitioners and non-yoga practitioners.

TABLE-2, Showing The Comparison Of Total Psychological Health Of Yoga And Non-Yoga Practitioners:

\begin{tabular}{|l|l|l|l|l|}
\hline Groups & N & M & S.D & T \\
\hline $\begin{array}{l}\text { Yoga } \\
\text { practitioners }\end{array}$ & 30 & 24.37 & 1.884 & 5.008 \\
\hline $\begin{array}{l}\text { Non Yoga } \\
\text { practitioners }\end{array}$ & 30 & 20.93 & 3.248 & 5.008 \\
\hline
\end{tabular}

Table-2 shows the comparison between the psychological health of yoga practitioners and nonyoga practitioners. The mean score of yoga practitioners is 24.37 and for non-yoga practitioners is 20.93 and their standard deviations are 1.884 and 3.248 respectively. The t-value is 5.008 which is significant at .01 level indicating a significant difference between total psychological health of yoga and non-yoga practitioners. 
TABLE-3, Showing the comparison of the social relationships of the yoga and non-yoga practitioners:

\begin{tabular}{|l|l|l|l|l|}
\hline Groups & $\mathbf{N}$ & $\mathbf{M}$ & S.D & T \\
\hline $\begin{array}{l}\text { Yoga } \\
\text { practitioners }\end{array}$ & 30 & 11.73 & 1.552 & 3.259 \\
\hline $\begin{array}{l}\text { Non Yoga } \\
\text { practitioners }\end{array}$ & 30 & 10.10 & 2.264 & 3.259 \\
\hline
\end{tabular}

Table-3 shows the comparison between the social relationships of yoga practitioners and nonyoga practitioners. The mean score of yoga practitioners is 11.73 and for non-yoga practitioners is 10.10 and their standard deviations are 1.552 and 2.264 respectively. The t-value is 3.259 which is significant at .01 level indicating a significant difference between the social relationships of yoga and non-yoga practitioners.

TABLE-4, Showing the comparison of the environment of yoga and non-yoga practitioners:

\begin{tabular}{|l|l|l|l|l|}
\hline Groups & N & M & S.D & T \\
\hline $\begin{array}{l}\text { Yoga } \\
\text { practitioners }\end{array}$ & 30 & 30.43 & 3.471 & 3.428 \\
\hline $\begin{array}{l}\text { Non Yoga } \\
\text { practitioners }\end{array}$ & 30 & 27.37 & 3.459 & 3.428 \\
\hline
\end{tabular}

Table-4 shows the comparison between the environment of yoga practitioners and non-yoga practitioners. The mean score of yoga practitioners is 30.43 and for non-yoga practitioners is 27.37 and their standard deviations are 3.471 and 3.459 respectively. The t-value is 3.428 which is significant at .01 level indicating a significant difference between the environment of yoga and non-yoga practitioners.

TABLE-5, Showing the comparison of the total quality of life of yoga and non-yoga practitioners:

\begin{tabular}{|l|l|l|l|l|}
\hline Groups & N & M & S.D & T \\
\hline $\begin{array}{l}\text { Yoga } \\
\text { practitioners }\end{array}$ & 30 & 93.40 & 6.836 & 5.714 \\
\hline $\begin{array}{l}\text { Non Yoga } \\
\text { practitioners }\end{array}$ & 30 & 81.90 & 8.648 & 5.714 \\
\hline
\end{tabular}

Table- 5 shows the comparison between the total quality of life of yoga practitioners and nonyoga practitioners. The mean score of yoga practitioners is 93.40 and for non-yoga practitioners is 81.90 and their standard deviations are 6.836 and 8.648 respectively. The t-value is 5.714 which is significant at .01 level indicating a significant difference between the total quality of life of yoga and non-yoga practitioners. 


\section{CONCLUSION:}

The research study has described various aspects of the effectiveness of yoga, exercise and prayer on the quality of life. People are often neglected of their health and inner peace. They try to find happiness in materialistic world but fail to do so because there is no connectivity between their mind and body. Until and unless our soul and mind will not be in the state of complete peace we are not able to lead a satisfactory life. Not only the healthy soul is important but also the healthy body is very essential. With regular practise of yoga one can gain the inner harmony as well as it helps in controlling a number of medical problems like respiratory, digestive, hormonal, etc. Exercise helps in maintaining the fitness of the body and avoids obesity, heart problems, etc. Prayer helps in connecting with the God and provides a sense of satisfaction. Although people now a days are becoming aware of their problems and the effectiveness of the methods discussed above but still there is a need of more research in this field.

\section{REFERENCES:}

Anonymous (19196).Summary of the Surgeon General's Report Addressing Physical Activity and Health. Nutritional Reviews, 54(9), 280-289.

Barnes PM, Bloom B, Nahin RL. Complementary and alternative medicine use among adults and children: United States, 2007. CDC National Health Statistics Report \#12. 2008

Brown RP, et al. "SudarshanKriya Yogic Breathing in the Treatment of Stress, Anxiety, and Depression: Part I: Neurophysiologic Model," Journal of Alternative and Complementary Medicine (Feb. 2005): Vol. 11, No. 1, pp. 189-201.

Brown RP, et al. "SudarshanKriya Yogic Breathing in the Treatment of Stress, Anxiety, and Depression: Part II:Clinical Applications and Guidelines,” Journal of Alternative and Complementary Medicine (Aug. 2005): Vol. 11, No. 4, pp. 711-17.19-2026

Centers for Disease Control and Prevention. "Physical Activity > Levels among Children Aged 9-13 Years—United States, 2002." Morbidity and Mortality Weekly Report 52 (2003): 785-88.

Health and Quality of Life Outcomes201311:187 DOI: 10.1186/1477-7525-11-187.

Iran J Nurs Midwifery Res. 2010 Dec; 15(Suppl1): 296-301.

Sherman KJ, Cherkin DC, Wellman RD, et al. A randomized trial comparing yoga, stretching, and a self-care book for chronic low back pain. Archives of Internal Medicine. 2011;171(22):20 